\title{
An Experimental Approach to the Application of Digital Image Correlation to Small Punch Creep Testing
}

\author{
Melody van Rooyen ${ }^{1 *}$, Thorsten Becker ${ }^{1 * *}$, and Mahmoud Mostafavi ${ }^{2^{* * *}}$ \\ ${ }^{1}$ Department of Mechanical and Mechatronic Engineering, University of Stellenbosch, Private Bag \\ X1, Matieland 7602, South Africa \\ ${ }^{2}$ Department of Mechanical Engineering, University of Bristol, Bristol, BS8 1TR, United Kingdom
}

\begin{abstract}
Deterioration assessment of materials is essential to the continued effective operation of critical components operating, at high temperatures and stresses, in thermal power plants. Within progressive inspection strategies, small punch creep testing (SPCT) presents an effective method for establishing the degree of creep exhaustion of in-service power engineering alloys on account of the small volume of material required (Ø8 $\mathrm{mm} \times 0.5 \mathrm{~mm}$ discs). These tests make the application of complex strain fields, analogous to the strain field experienced by the service components, possible. In addition, this work explores the application of a noncontact digital image correlation (DIC) method to the full-field measurement of strains which is not possible through traditional extensometry. The accelerated SPCT tests were performed on $12 \% \mathrm{Cr}$ ex-service steels subjected to $600{ }^{\circ} \mathrm{C}$. Experimental methodologies and challenges associated with ex situ DIC-SPCT are discussed including equipment and parameter selection, speckle pattern application, preforming requirements and loading method. It is shown that the developed DIC technique using a stereo microscope, airbrushed speckle patterns, sombrero-preformed discs and interrupted tests can be used to compare surface strain development in various aged forms of the ex-service steel. Such an approach is valuable to understanding strain development in small punch tests and to assist in the comparative damage assessment of ex-service power plant materials.
\end{abstract}

\section{Introduction}

Small punch testing (SPT) has gained increased attention in the maintenance programmes of aging power plants. Typical constant-force small punch creep testing (SPCT) involves penetrating a disc of material using a hemispherical punch or ball at constant load, high temperatures and within an inert atmosphere whilst punch displacement and/or disc deflection is measured. Such an approach boasts an advantage for life assessment of inservice plant materials due to the small specimen sizes (Ø8 mm, $0.5 \mathrm{~mm}$ thickness) that makes sample extraction possible without impairing the operability of the host component

\footnotetext{
*e-mail: melzvanrooyen@sun.ac.za

**e-mail: tbecker@sun.ac.za

***e-mail: m.mostafavi@bristol.ac.uk
} 
[1]. Site-specific material property assessment of, for instance, welds and heat-affected zone (HAZ) regions, is also possible through this technique.

The popularity of the technique is highlighted in the extensive literature presence of applications to in-service power plant materials. Applications of SPT include tensile property measurement from load-displacement curves of aged rotor steels [2] as well as across different weld regions [3]. This technique was also expanded to characterise the embrittlement of aged materials through the measurement of temperature-dependent fracture toughness and energy [2]. The SPCT has been applied to creep property measurement of numerous new [4], aged base [5] and weldment [6] rotor, steam piping and boiler steels. Several researchers have also employed SPCT within the framework of the European collaborative COPERNICUS project with the aim of assessing the remnant life of X20CrMoV12-1 (X20) and other steels using creep stress exponents and activation energies from Dorn relations [7].

Despite the wide-scale applications of SPCT, the technique involves several challenges that are not normally associated with traditional testing including sensitivities to: geometrical uncertainties in the experimental setup such as the indenter size and eccentricity from the disc centre [8]; upper die clamping conditions [9]; differences in disc specimen thickness with a direct effect on creep rupture times [10]; atmospheric conditions [11]; oxidation [12] as well as friction between punch components and the disc [13].

Although these issues have been largely mitigated through the introduction of a code of practice [14] with strict specifications placed on disc and punch geometry and test procedures, the interpretation of the SPCT data (displacement and load) and its equivalence to standard creep test data (specifically strain and stress) remains the focal point of many research works due to the complex stress and strain states [15]. For establishing the equivalent stress, conversion factors (calculating equivalent stress from load) based on Chakrabarty membrane stretching theory [16] as well as stress distributions calculated from finite element (FE) modelling [13] have been employed. Maximum equivalent strains can be estimated from simple analytical relationships with the central deflection [17], thickness changes at the thinnest point in the disc [18] as well as from FE models [19]. The former two methods only provide single point strain estimates whereas the strain field output from FE analysis is sensitive to numerous unknown parameters, such as friction coefficients and the selected creep model parameters [20]. The current literature presents with few attempts to measure full-field, surface strain maps of SPCT specimens.

To this end, digital image correlation (DIC) is considered an ideal candidate for full-field strain measurement of SPCT disc samples due to its noncontact nature as well as its lack of restriction on measurement length scales [21]. Aydin et al. [22] applied two-camera DIC to the in situ measurement of the fracture heights of steel sheets during an Erichsen cupping test which shares some similarities with a small punch test. However, no strain distributions were presented from the DIC data. Strain measurement using a stereo microscope DIC technique during a hydraulic bulge test on specimens with dimensions similar to that of SPCT was achieved by Ren et al. [23]. Recently, full-field deformations were mapped during room temperature small punch tensile tests using in situ DIC [24]. There have been few attempts to extend DIC to strain mapping during SPCT conducted at higher temperatures.

This work investigates the feasibility of using an ex situ stereo microscope DIC technique for the measurement of strain fields across a small punch creep tested disc of new and exservice X20 steel and weldment. This includes: the design of a small punch creep setup together with the design of a stereo microscope DIC setup to capture images with a durable, high resolution speckle pattern for strain measurement; development of a strain-processing algorithm; selection of disc preforming method and specimen loading method (including repeated loading on the same disc specimen or interrupted loading on different disc specimens). 


\section{Experimental design}

Due to the physical difficulties associated with obtaining images on a fine scale in a confined space $(<\varnothing 4 \mathrm{~mm}$ viewing field) at high temperatures and under argon atmosphere, the present work is confined to DIC images that are captured ex situ. The following sections describes the experimental setup required to achieve this, including selected materials and disc geometry, SPCT rig, speckle pattern application and stereo microscope DIC setup and processing methods.

\subsection{Materials and specimen geometry}

The chemical composition of the X20 material (supplied in pipe sections from a local power utility company) used in this study is given in Table 1. Three material types are outlined: "new" X20 is as-received material with no service exposure; "low" service exposure X20 is an ex-service material exposed to temperatures of $545{ }^{\circ} \mathrm{C}$ and pressures of $17 \mathrm{MPa}$ for about $130000 \mathrm{~h}$ of operation; and "high" service exposure X20 is an ex-service material exposed to conditions of $543{ }^{\circ} \mathrm{C}$ and $18.1 \mathrm{MPa}$ for approximately $156000 \mathrm{~h}$ of operation. "Low" and "high" service exposure X20 were categorised based on average cavity density counts from scanning electron micrographs with values of $119 \pm 48$ cavities $/ \mathrm{mm}^{2}$ and $489 \pm 451$ cavities $/ \mathrm{mm}^{2}$, respectively [25]. Weldment material was extracted from the fusion region between high and low service exposure X20.

Rods of $8 \mathrm{~mm}$ diameter longitudinally aligned with the pipe axis were cut from the centre of the pipe thickness as shown in Figure 1. Discs of $\sim 1.0 \mathrm{~mm}$ were wire cut from the rods and then polished down using 220 grit followed by 1000 grit silica carbide paper on both sides until an average thickness of approximately $0.5 \pm 0.01 \mathrm{~mm}$ was measured.

Table 1. Chemical composition of new and ex-service X20 steels in wt\% (balance iron)

\begin{tabular}{|c|c|c|c|c|c|c|c|c|c|}
\hline Material & \multicolumn{7}{|c|}{ Elements } \\
\hline & $\mathbf{C}$ & $\mathbf{S i}$ & $\mathbf{M n}$ & $\mathbf{C r}$ & $\mathbf{M o}$ & $\mathbf{N i}$ & $\mathbf{V}$ & $\mathbf{P}$ & $\mathbf{S}$ \\
\hline New & 0.21 & 0.19 & 0.58 & 11.6 & 0.88 & 0.76 & 0.25 & 0.015 & 0.004 \\
\hline Low & 0.19 & 0.36 & 0.63 & 11.7 & 0.91 & 0.67 & 0.32 & 0.013 & $<0.005$ \\
\hline High & 0.17 & 0.20 & 0.59 & 11.6 & 0.94 & 0.71 & 0.34 & 0.015 & $<0.005$ \\
\hline
\end{tabular}

\subsection{Small punch creep testing}

\subsubsection{Small punch design}

The geometric detail of the punch body and a photograph of the punch rig is shown in Figure $2 \mathrm{a}$ and $\mathrm{b}$, respectively. The punch was designed in accordance with the CEN CWA 15627 guidelines [14] and consists of an alumina oxide ceramic ball of $2.5 \mathrm{~mm}$ diameter and a Nimonic 80A punch body. Load is applied at $2 \mathrm{~N} / \mathrm{s}$ using an Instron 1341 servohydraulic tester through the punch head onto the ceramic ball, which then causes the disc to bulge into a $4 \mathrm{~mm}$ diameter recess. Primary creep initiates when a maximum load is reached and maintained. Temperature is measured by a K-type thermocouple positioned against the disc and is kept within $2{ }^{\circ} \mathrm{C}$ of the setpoint as the punch is heated within a single-zone tube 
furnace. The periphery of the disc is clamped by the upper die as in a classic "small punch bulge test" as outlined in CWA 15627. Argon gas is supplied to the bottom disc surface by a capillary tube at a rate of $0.2 \mathrm{~L} / \mathrm{min}$. Deflection of the punch was measured using an LVDT with a resolution of $1 \mu \mathrm{m}$.

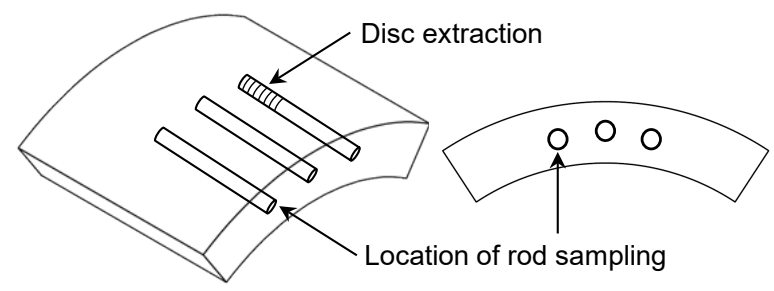

Fig 1. Sampling schematic of rods from which discs are wire cut
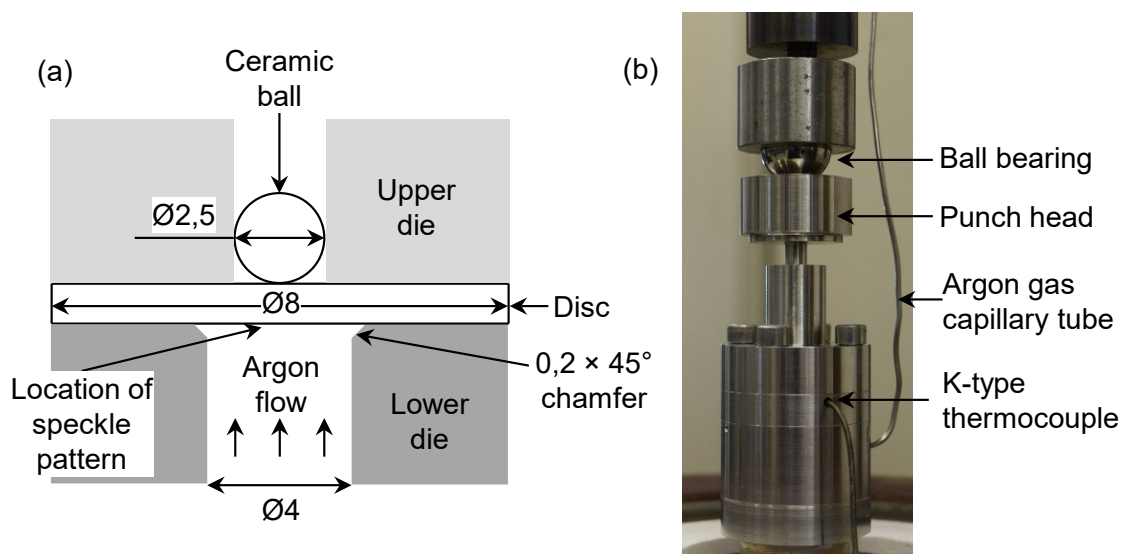

Fig 2. (a) Dimensions of the punch body geometry (supplied in $\mathrm{mm}$ ) and (b) photograph of small punch creep setup

\subsubsection{Preforming}

To prevent speckle pattern flaking due to excessive strains, the discs are prebulged into "sombrero" shapes at the same temperature and to the same load used in the subsequent creep test. Such an approach was shown by Ule et al. [10] to have no effect on the creep curve development in terms of rupture time and minimum creep rates. Following the prebulging, the load is removed, and the preformed disc is removed for speckle patterning according to the procedure outlined in Section 2.3.

\subsubsection{Ex situ specimen loading method}

To remove tested discs from the small punch rig for the ex situ acquisition of DIC images, continuous loading of specimens is not possible and disc reloading methods are required. Two methods were explored, namely, interrupted tests and retests. Interrupted tests involve the removal of a tested disc after a specified period of constant load application, capturing DIC images as described in Section 2.4 and subsequently inserting another untested, preformed disc to be subjected under the same maximum load and temperature conditions as before for progressively longer times. This method allows semi-continuous monitoring of 
strain but is specimen intensive. Retesting, on the contrary, involves reloading the same (previously tested) disc after DIC imaging for subsequent testing under the same conditions as prior testing. Although fewer specimens are required through disc reuse, softening or hardening effects on creep strain development are of concern [26]. For both methods, the test is stopped when the load is removed, followed by gradual cooling and removal of the crept disc for DIC imaging.

\subsection{Speckle pattern application}

The preformed surface of the disc was ultrasonically cleaned with acetone and coated with white VHT Flameproof matte, heat-resistant paint. Because speckle sizes produced from normal spray can application are too large $(30-80 \mu \mathrm{m})$ for the current work, an airbrush was employed. A fine mist of undiluted VHT matte black speckles was applied to the wet paint surface using a generic model SP180KTG airbrush with a $0.2 \mathrm{~mm}$ needle, $30 \mathrm{~cm}$ stand-off distance, a medium airflow (based on three full turns of the air regulating screw) and $25 \mathrm{kPa}$ working pressure. These settings were selected based on the guidelines offered by Lionello and Cristofolini [27] for applying optimal speckle distributions.

Resulting speckle sizes ranged from $10-13 \mu \mathrm{m}$ as measured using image thresholding in ImageJ [28] of micrographs taken by a Zeiss Imager M2 Axio light microscope at 200× magnification. With the magnification factor of 0.24 pixels $/ \mu \mathrm{m}$ encountered in the calibrated DIC images, the average speckle size was therefore covered by approximately 3 pixels as recommended by Schreier et al. [29] for optimal correlation. The speckle pattern, as shown in Figure $3 \mathrm{~b}$, was air cured for $24 \mathrm{~h}$ before testing to harden the pattern for handling.
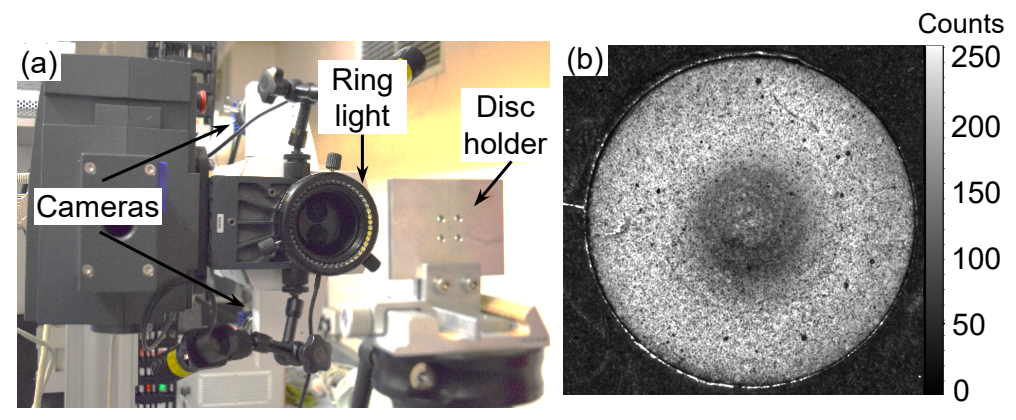

Fig 3. Photograph of the (a) stereo microscope DIC setup and (b) an example view of a speckled preformed disc

\subsection{Stereo-microscope digital image correlation setup}

The patterned sombrero-shaped disc (shown in Figure 3b) is recorded using the DIC hardware summarised in Table 2. Image acquisition was performed using a Zeiss SteREO Discovery.V12 stereo microscope retrofitted by LaVision to include two cameras and 3D micropositioning translation stages within an integrated system. Diffuse illumination was provided by a $7 \mathrm{~W}$, pure white colour temperature ring light mounted over the microscope lens. Disc samples were mounted on a sample holder fixed to a rigid tripod at about $240 \mathrm{~mm}$ from the lens front. A photograph of the setup is provided in Figure 3a. Prior to creep testing, a reference image is taken of the painted, preformed disc with markings made on the specimen holder to assist in aligning the disc to its original (prior to testing) position. Following testing, the creep tested disc is aligned and again imaged, and the process is repeated for subsequent tests. 
Table 2. DIC hardware details for small punch creep test

\begin{tabular}{|c|c|}
\hline Cameras & $\begin{array}{c}\text { Imager M-lite 5M on a Zeiss SteREO Discovery. V12 stereo- } \\
\text { microscope }\end{array}$ \\
\hline Image resolution & $2464 \times 2056$ pixels ${ }^{2}$ \\
\hline Lighting & 48 LED VisiLight R-LED-66 ring light $(7 \mathrm{~W})$ \\
\hline Lens & Achromat S lens, $\times 0.3$ magnification \\
\hline Aperture & Open position \\
\hline Field of view & $10.5 \times 8.7 \mathrm{~mm}{ }^{2}$ \\
\hline Image magnification & 240 pixels $/ \mathrm{mm}^{\circ}$ \\
\hline Stereo-angle & $5.8^{\circ}$ \\
\hline Free working distance & $236 \mathrm{~mm}$ \\
\hline $\begin{array}{c}\text { Patterning method } \\
\text { Approximate pattern } \\
\text { feature size }\end{array}$ & White, heat-resistant base coat, fine black airbrushed speckles \\
\hline
\end{tabular}

\subsection{Processing}

Due to the inherent complexities of the stress and strain state of small punch testing [17], DIC measured displacements were fitted with a piecewise second-order polynomial over a square window of 11 points using MATLAB ver. R2020a. Prior to fitting, outlier removal based on values greater than three local standard deviations from the local mean was performed to eliminate spurious measurements caused by image artefacts (for instance, dust particles on the microscope lenses). Strains are obtained through differentiation of the fitted displacement fields. A summary of the software parameters is provided in Table 3. For improving the disc alignment relative to the reference disc position, subpixel rigid body shift and rotation correction is performed by using correlation windows of 121 pixels size on larger speckle features on the disc periphery.

\subsection{Rigid body displacement tests}

In order to characterise displacement variance and bias error in the current setup, baseline noise and rigid body translation tests were conducted, respectively, according to Jones and Iadicola [30] and the processing parameters outlined in Table 3. The maximum applied translations were selected based on the anticipated deformations resulting from the SPCT [31]. Comparisons between applied and DIC in-plane and out-of-plane displacements are shown in Figure 4a and b, respectively. Displacement measurements correspond well in both directions with average root-mean-square values of 8 and $9 \mu \mathrm{m}$, respectively.

Insignificant differences were noted in the error analysis for other subset sizes $(21-81$ pixels). Consequently, a subset size of 41 pixels was selected based on the speckle size analysis discussed in Section 2.3. This results on average in $7 \times 7$ speckles per subset 
(assuming $50 \%$ speckle coverage) and a displacement measurement spatial resolution of about $250 \mu \mathrm{m}$. Self-correlation tests performed on a set of five stationary images using the selected subset size resulted in baseline displacement and strain errors as shown in Table 3.

Table 3. DIC software details for small punch creep test

\begin{tabular}{|c|c|}
\hline DIC software & LaVision DaVis, 8.4.0 \\
\hline Subset size & 41 pixels $(0.17 \mathrm{~mm})$ \\
\hline Step size & 10 pixels $(0.04 \mathrm{~mm})$ \\
\hline $\begin{array}{c}\text { Displacement noise } \\
\text { floor }\end{array}$ & In-plane: 0.03 pixels $(0.11 \mu \mathrm{m})$, Out-of-plane: 0.2 pixels $(0.8 \mu \mathrm{m})$ \\
\hline Strain noise floor & $32 \mu \varepsilon$ (averaged between vertical and horizontal directions) \\
\hline Subset shape function & First-order \\
\hline Matching criterion & Zero-normalised sum of square differences (ZNSSD) \\
\hline Grey level interpolant & Sixth-order spline \\
\hline $\begin{array}{l}\text { Prefiltering of } \\
\text { displacements }\end{array}$ & $\begin{array}{l}\text { Spatial piecewise second-order fit with moving mean outlier } \\
\text { removal }\end{array}$ \\
\hline Strain window & 11 data points \\
\hline $\begin{array}{l}\text { Virtual strain gauge } \\
\text { (VSG) size }\end{array}$ & 131 pixels $(0.55 \mathrm{~mm})$ \\
\hline
\end{tabular}
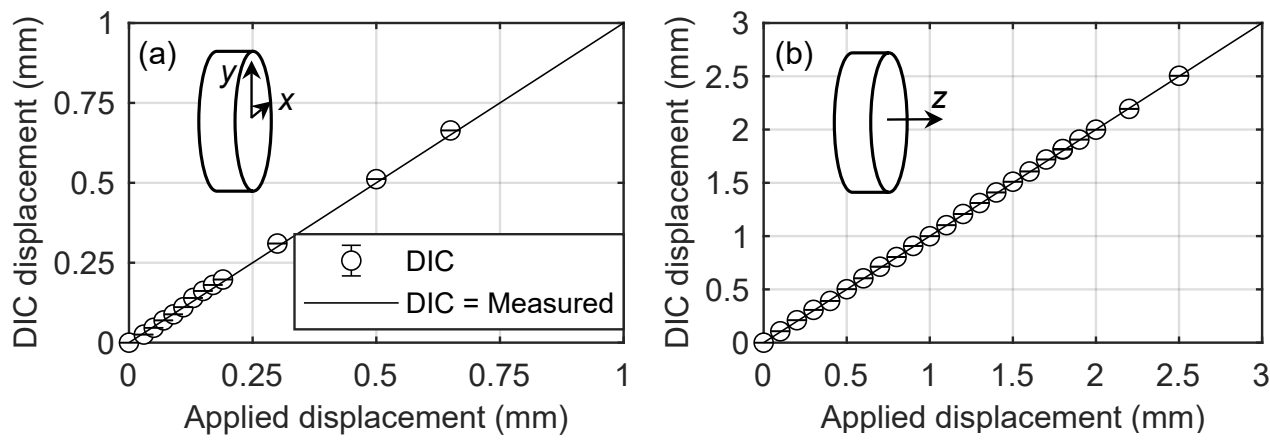

Fig 4. Comparison between DIC measured displacements and applied translations for (a) in-plane and (b) out-of-plane rigid body tests for a $41 \times 41$ pixels $^{2}$ subset and 10-pixel step size.

\section{Results and discussions}

\subsubsection{Interrupted tests versus retests}

A demonstration of the ex situ small punch strain mapping (in terms of maximum normal strain $\varepsilon_{\text {norm }}$ ) using DIC is shown in Figure $5 \mathrm{~b}$-f along with the corresponding time-punch displacement curves (Figure 5a) for interrupted tests of new, low service exposure and 
weldment X20. A load of $520 \mathrm{~N}$ and a temperature of $630{ }^{\circ} \mathrm{C}$ was selected in order to accelerate creep curve development within $3 \mathrm{~h}$. The strain maps are measured when the tests are interrupted at the indicated times on the time-displacement curves. Positions (in terms of radial distance, $r_{\max }$, from disc centre) of the local maximum normal strain $\left(\varepsilon_{\max }\right)$ are also indicated in Figure 5b-f.

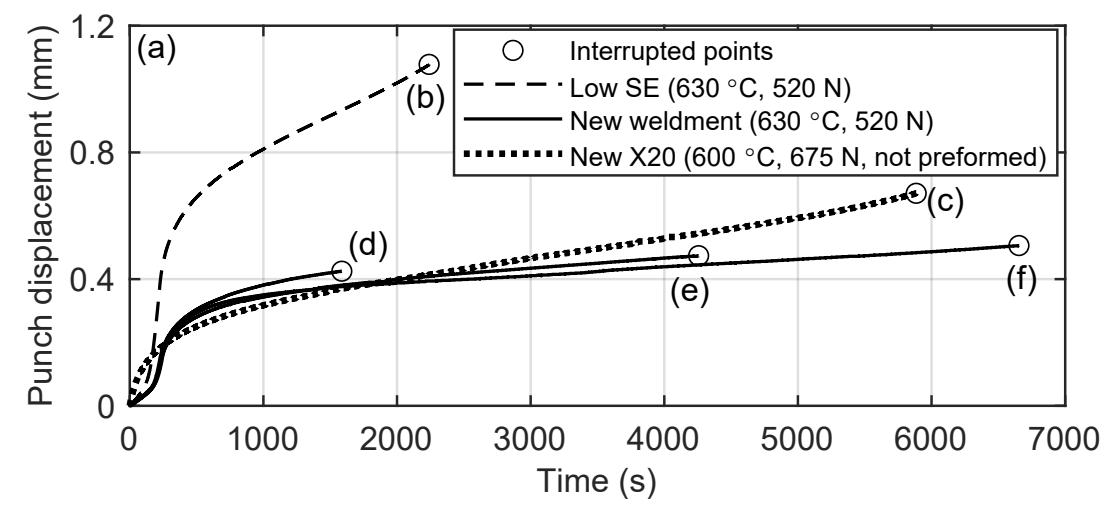

- Position of maximum normal in-plane strain
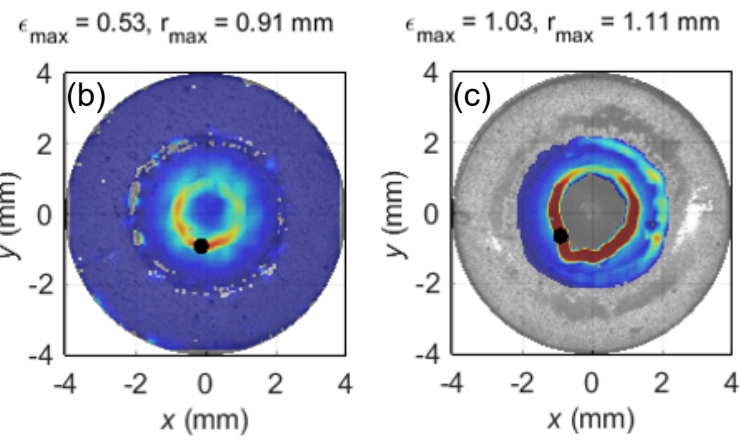

$\epsilon_{\max }=0.17, r_{\max }=0.91 \mathrm{~mm}$

$$
\epsilon_{\max }=0.22, r_{\max }=1.02 \mathrm{~mm}
$$

$$
\epsilon_{\max }=0.25, r_{\max }=0.94 \mathrm{~mm}
$$
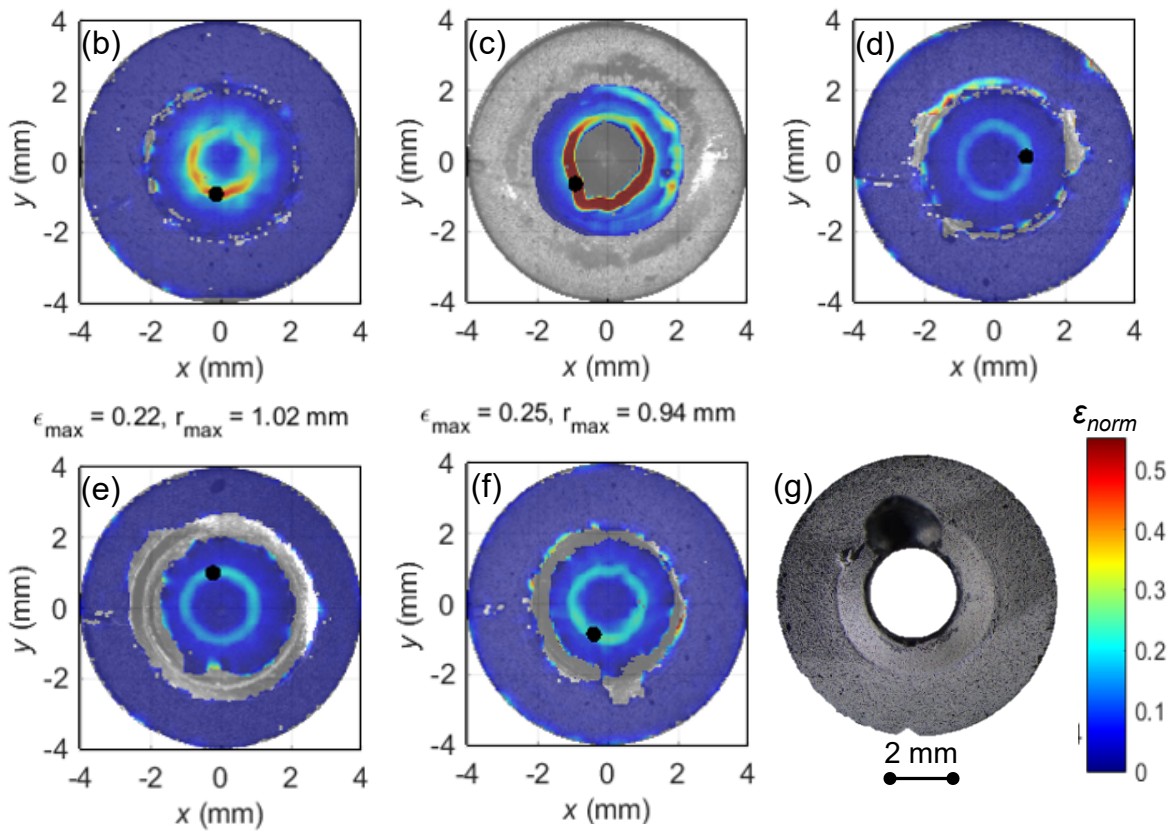

Fig 5. (a) Time-punch displacement curves of interrupted small punch creep tests of new, low service exposure and weldment X20 with corresponding (b-g) maximum normal strain maps. SE = service exposure.

Several observations can be made from the resulting distributions of maximum normal strains on the disc surfaces. Firstly, strains on the disc periphery are near zero due to the clamping mechanism of the upper die. Secondly, a concentrated annulus of high strains forms around the centre of the disc and corresponds to the contact area between the ball and the disc [32]. This ring proceeds to widen and increase in strain magnitude with increasing punch 
displacement as a larger area of the ball contacts the deforming disc, resulting in a switch from plastic bending behaviour to plastic membrane stretching as the disc deflection exceeds the initial thickness of the disc [17]. Moreover, the low service exposure X20 demonstrates less creep resistance than the weldment for identical testing conditions. As shown in Figure $5 \mathrm{~b}$, this results in higher strain values and a thicker annulus than for the weldment strain maps. This observation also confirms the FE predictions of Cortellino et al. [33] where peak equivalent plastic strains and simulated creep damage develop at the base of the disc at offcentre contact regions with the punch. This strain concentration also correlates with the locations of through thickness cracks that results in disc failure for high service exposure parent X20 (Figure 5g).

Maximum normal strain maps for retested discs of new X20 weldment are shown in Figure 6. In comparison to the interrupted tests of the new weldment (Figure 5a), the retests result in accelerated creep with shorter times to rupture. For example, the retested sample accelerates into the tertiary regime within $3250 \mathrm{~s}(0.9 \mathrm{~h})$ whereas the interrupted sample (curve (f) in Figure 5, for instance) remained in the primary creep regime for $>6000 \mathrm{~s}(1.67$ h) of testing. This is possibly due to softening effects brought about by primary creep regeneration which causes increased creep rates following an unloading-loading cycle (point (b) in Figure 6a, for instance) as a result of a reduction in dislocation densities [26].
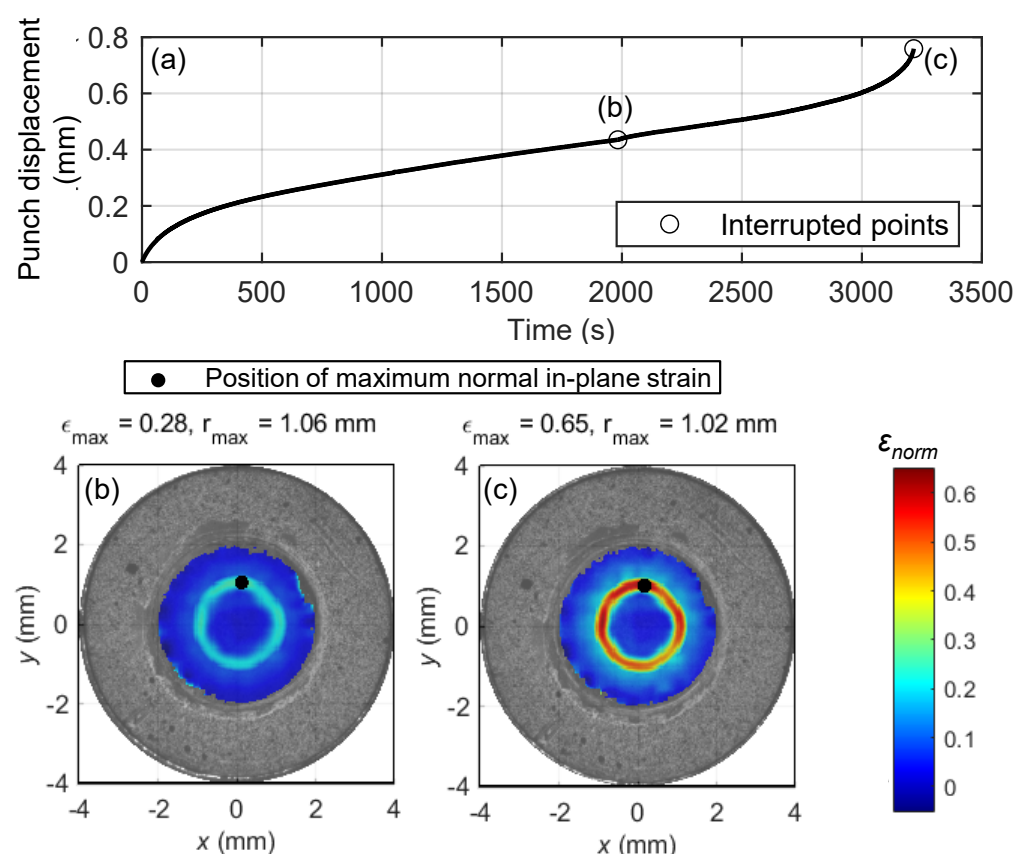

Fig 6. (a) Time-punch displacement curves of a small punch creep retest of new weldment X20 specimen with corresponding (b-c) maximum normal strain maps.

Speckle pattern quality completely degrades for highly strained areas as in the case of Figure 5c where a flat disc of new X20 was subjected to creep loading prior to any preforming. In this case, the central bulge could not be correlated by the DIC software, thereby affirming the need for a preforming process before speckle pattern application. Similar paint degradation was apparent in the retested discs for several load-unloading cycles. Careful handling of retested discs is also necessary due to the embrittlement of the speckle pattern painted layer following repeated testing. 


\subsubsection{Comparison between new and service-exposed X20}

Figure 7 shows the comparison of the maximum normal strain maps of new and high service exposure X20 discs obtained using interrupted tests at $600{ }^{\circ} \mathrm{C}$ and $500 \mathrm{~N}$.
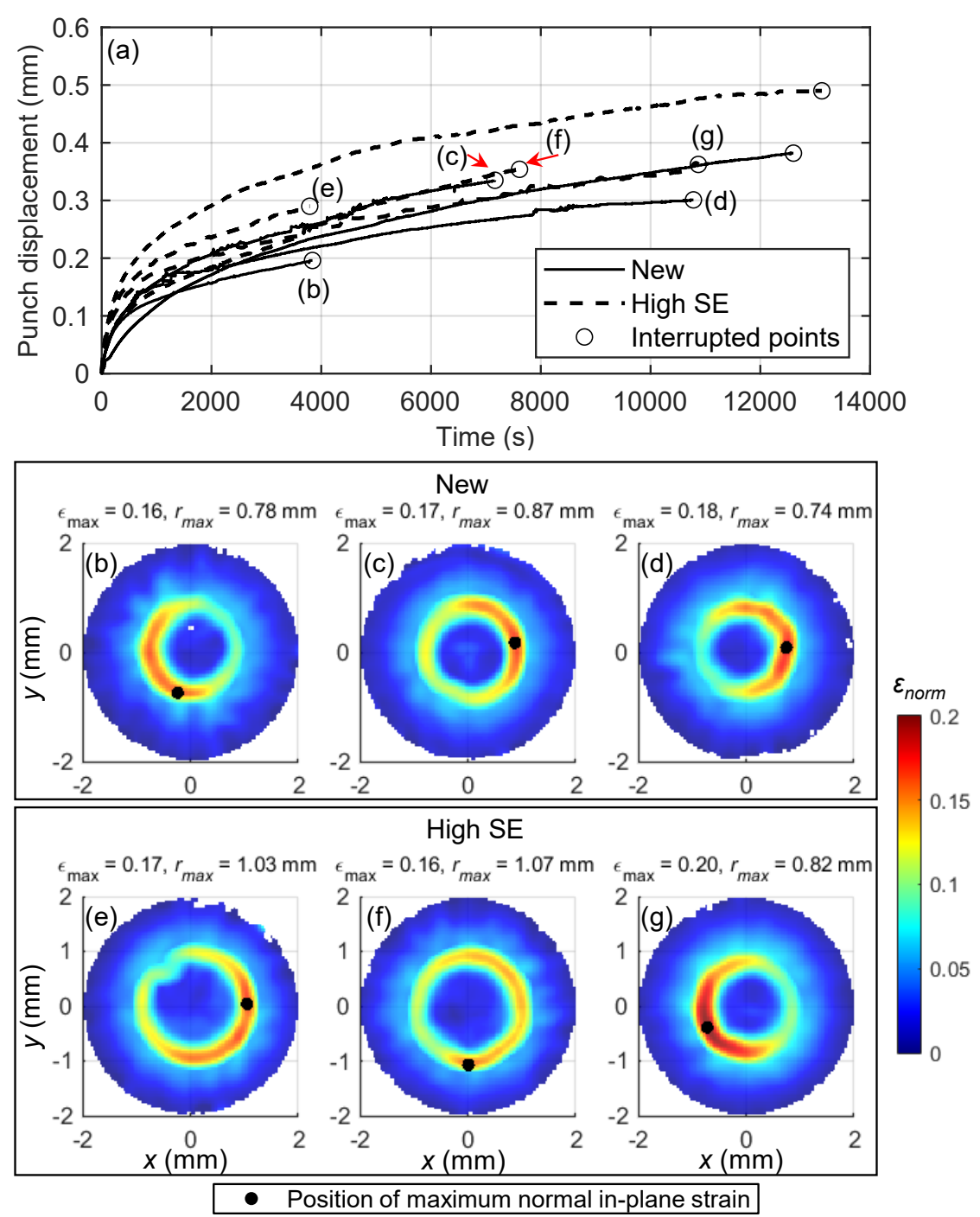

Fig 7. (a) Time-punch displacement curves of interrupted small punch creep tests of new and high service exposure $\mathrm{X} 20$ at $600{ }^{\circ} \mathrm{C}$ and $500 \mathrm{~N}$ with corresponding (b-g) maximum normal strain maps. $\mathrm{SE}=$ service exposure.

Firstly, scatter in time-displacement curves is evident, particularly for the high service exposure X20. This could be attributed to nonuniformity of cavity density distributions in the high service exposure material [25] as well as difficulty in aligning the punch ball within the preformed bulge. DIC measured strain maps can also be used to assess the geometric concentricity and uniformity of clamping conditions by considering the deviations from axisymmetric distributions as shown by the unsymmetrical strain concentration rings in Figure $7 \mathrm{~b}-\mathrm{g}$. Despite these limitations, higher strains within wider annulus strain bands are evident for the service-exposed X20, indicating larger deformations for the same loading 
conditions. Strain maps obtained for the unlabelled curves in Figure 7a contained outlier values and decorrelated regions due to the degraded speckle patterns at these higher strains and are not presented here.

\section{Conclusions and prospects}

An experimental technique for the ex situ acquisition of strain maps of small punch creep tested power plant steels using DIC is presented. Challenges of speckle pattern resolution, speckle pattern flaking and method of specimen reloading for ex situ image acquisition is addressed through airbrushed, heat resistant speckles, preforming into sombrero-shaped discs and interrupted tests of different discs or retests of the same disc, respectively. Interrupted tests are sensitive to differences in local cavity densities of service-exposed material as different discs are employed (extracted from different locations of the same material type). Retests are more material efficient with the use of a single disc and are not sensitive to property variations between various discs. However, softening effects prevent the assessment of the "true" creep response. Larger strains and thicker strain bands are evident for small punch creep tested high service exposure X20 when compared to new X20. Strain maps are also able to indicate deviations from coaxial alignment of the punch head and disc preformed bulge.

The conversion of load-displacement data output from small punch testing into stressstrain relations required by creep analysis has long been a challenge encountered by researchers [17]. This work has highlighted the application of full-field strain mapping to SPCT. Future aims for this technique include combining the DIC strain fields with data from other streams (such as FE stress fields) to aid damage assessment using continuum damage mechanics models. Furthermore, in situ combinations of DIC with small punch testing precludes limitations regarding speckle pattern durability, punch ball misalignment, cyclic softening effects and the need for laborious interruptions of creep tests. This forms part of ongoing work aimed at material-efficient damage extraction methods for service-retrieved power plant steels.

The financial support by the National Reserach Foundation, South Africa is thankfully acknowledged.

\section{References}

1. J. P. Rouse, W. Sun, and T. H. Hyde, J. Strain Anal. Eng. Des. 48, 494 (2013)

2. M. Madia, S. Foletti, G. Torsello, and A. Cammi, Eng. Fail. Anal. 34, 189 (2013)

3. S. Komazaki, T. Kato, Y. Kohno, and H. Tanigawa, Mater. Sci. Eng. A 510-511, 229 (2009)

4. M. Selent, M. Abendroth, and M. Kuna, Trans. Indian Inst. Met. 69, 629 (2016)

5. S. Yang, X. Ling, and Y. Zheng, Mater. Sci. Eng. A 685, 1 (2017)

6. D. T. Blagoeva and R. C. Hurst, Mater. Sci. Eng. A 510-511, 219 (2009)

7. B. Ule, T. Sustar, T. Rodic, F. Dobes, K. Milicka, V. Bicego, S. Tettamanti, K. Maile, C. Schwarzkopf, M. Whelan, J. Klaput, and R. H. Kozlowski, Technol. Law Insur. 4, 283 (1999)

8. S. Komazaki, T. Nakata, Y. Kohno, and H. Tanigawa, Exp. Mech. 57, 487 (2017)

9. D. Andrés and P. Dymáček, Theor. Appl. Fract. Mech. 86, 117 (2016)

10. B. Ule, R. Strum, and V. Leskovsek, Mater. Sci. Technol. 19, 1771 (2003) 
11. T. Nakata, S.-I. Komazaki, Y. Kohno, and H. Tanigawa, Mater. Sci. Eng. A 666, 54 (2016)

12. K. Kobayashi and S. Takei, Influence of Testing Environment on SP Creep Rupture Lives, in Proc. ASME 2013 Press. Vessel. Pip. Conf., PVP, 14-18 July 2013, Paris, France (2013)

13. T. Nakata, S.-I. Komazaki, Y. Kohno, and H. Tanigawa, Mater. Sci. Eng. A 666, 80 (2016)

14. CEN, CWA 15627 Workshop Agreement: Small Punch Test Method for Metallic Materials (European Committee for Standardization, Brussels, 2007)

15. T. H. Hyde, M. Stoyanov, W. Sun, and C. J. Hyde, J. Strain Anal. Eng. Des. 45, 141 (2010)

16. S. Holmström, Y. Li, P. Dymacek, E. Vacchieri, S. P. Je, R. J. Lancaster, D. Omacht, Z. Kubon, E. Anelli, J. Rantala, A. Tonti, S. Komazaki, M. Bruchhausen, R. C. Hurst, P. Hähner, M. Richardson, and D. Andres, Mater. Sci. Eng. A 731, 161 (2018)

17. Z. Yang and Z. wen Wang, Int. J. Press. Vessel. Pip. 80, 397 (2003)

18. T. Lee, F. A. Ibupoto, J. H. Lee, B. J. Kim, and M. K. Kim, Exp. Mech. 56, 395 (2016)

19. P. Dymáček and K. Milička, Mater. Sci. Eng. A 510-511, 444 (2009)

20. Z. Zhou, Y. Zheng, X. Ling, R. Hu, and J. Zhou, Mater. Sci. Eng. A 527, 2784 (2010)

21. T. A. Berfield, J. K. Patel, R. G. Shimmin, P. V. Braun, J. Lambros, and N. R. Sottos, Exp. Mech. 47, 51 (2007)

22. M. Aydin, X. Wu, K. Cetinkaya, M. Yasar, and I. Kadi, Eng. Sci. Technol. an Int. J.

21, 760 (2018)

23. M. Ren, J. Liang, L. Li, B. Wei, L. Wang, and Z. Tang, Rev. Sci. Instrum. 86, (2015)

24. V. D. Vijayanand, M. Mokhtarishirazabad, J. Peng, Y. Wang, M. Gorley, D. M.

Knowles, and M. Mostafavi, J. Nucl. Mater. 538, 152260 (2020)

25. M. van Rooyen, T. H. Becker, J. Westraadt, and G. Marx, MDPI Materials. 12, 3106 (2019)

26. X. Li, S. R. Holdsworth, S. Kalácska, L. Balogh, J. S. Park, A. S. Sologubenko, X. Maeder, S. Kabra, E. Mazza, and E. Hosseini, Mater. Des. 199, (2021)

27. G. Lionello and L. Cristofolini, Meas. Sci. Technol. 25, (2014)

28. S. Johannes, A.-C. Ignacio, F. Erwin, K. Verena, L. Mark, P. Tobias, P. Stephan, R. Curtis, S. Stephan, S. Benjamin, T. Jean-Yves, J. W. Daniel, H. Volker, E. Kevin, T. Pavel, and C. Albert, Nat. Methods 9, 676 (2012)

29. H. Schreier, J. J. Orteu, and M. A. Sutton, Image Correlation for Shape, Motion and Deformation Measurements: Basic Concepts, Theory and Applications (Springer, New York:, 2009)

30. E. M. C. Jones and M. A. Iadicola, Eds., A Good Practices Guide for Digital Image Correlation (International Digital Image Correlation Society (iDICs), 2018)

31. M. Stoyanov, Investigation of Small Punch Creep Testing, PhD thesis, University of Nottingham, 2013

32. X. Chen, X. Xie, J. Sun, and L. Yang, SAE Int. J. Mater. Manuf. 5, 345 (2012)

33. F. Cortellino, J. P. Rouse, B. Cacciapuoti, W. Sun, and T. H. Hyde, Exp. Mech. 57, 1193 (2017) 